Original Research

\title{
Assessment of Durability of Bio-based Earth Composites
}

Aurélie Laborel-Préneron ${ }^{1,}{ }^{*}$, Paulina Faria ${ }^{2}$, Jean-Emmanuel Aubert ${ }^{1}$, Camille Magniont ${ }^{1}$

1. LMDC, INSA/UPS Génie Civil, 135 Avenue de Rangueil, 31077 Toulouse cedex 04, France; EMails: alaborel@insa-toulouse.fr; aubert@insa-toulouse.fr; c magnio@insa-toulouse.fr

2. CERIS and NOVA University of Lisbon, Department of Civil Engineering, 2829-516 Caparica, Portugal; E-Mail: paulina.faria@fct.unl.pt

* Correspondence: Aurélie Laborel-Préneron; E-Mail: alaborel@insa-toulouse.fr

Academic Editor: Hossein Hosseinkhani

Special Issue: Wastes, Residues and Byproducts for the Production of Construction Materials

Recent Progress in Materials

2021, volume 3, issue 2

doi:10.21926/rpm.2102016
Received: March 12,2021

Accepted: April 21,2021

Published: May 07,2021

\begin{abstract}
Bio-based earth composites present various environmental benefits, such as usable wastes, coproducts, abundant or renewable materials, etc. Moreover, the incorporation of bioaggregates in the earth matrix allows the buildings to act as an effective carbon sink. A growing number of studies are now focusing on the mechanical and hygrothermal properties of bio-based earth building materials. However, the durability of these types of material is a major concern, and knowledge of their various aspects is essential to anticipate maintenance and sustain the performance levels. Here, the durability of compressed earth composites, valorizing discarded earth containing 3\% of barley straw, hemp shiv, or rice husk, is investigated. Due to the lack of internationally recognized standards to assess the durability of earthen materials and products, we proposed some testing procedures and discussed their relevance. The addition of these three bioaggregates decreases stiffness, as estimated by ultrasound velocity, and improves the resistance to impact and erosion by water. However, water absorption under low pressure is increased, and dry abrasion resistance is decreased. Moreover, the rice husk composite presents the best compromise.
\end{abstract}

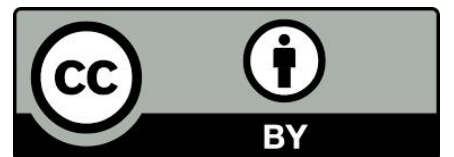

(C) 2021 by the author. This is an open access article distributed under the conditions of the Creative Commons by Attribution License, which permits unrestricted use, distribution, and reproduction in any medium or format, provided the original work is correctly cited. 


\section{Keywords}

Earth composite; straw; hemp shiv; rice husk; performance; durability

\section{Introduction}

Earth building materials are continuously being recognized for their large-scale availability, low environmental impact, and capacity to regulate indoor climate [1]. However, they can present major drawbacks, such as low resistance to liquid water, ductility, and significant shrinkage. These drawbacks are barriers to the spreading of earthen architecture, along with difficulty to understand and predict their long-term behavior, that is, durability [2]. Some of these drawbacks can be improved partially by the addition of plant aggregates and fibers [3-5], while some other drawbacks, such as susceptibility to fungal growth, can also occur [6]. These resources are renewable; they are by-products of agriculture or industry and available in huge amounts. Their use is, thus, environmentally friendly. Several studies have dealt with bio-sourced earth bricks or plasters [7-9]. However, few of them have focused on durability [10-12].

Biocomposites have been studied for different applications [13] and can contribute to the comfort and health of the buildings' occupants. In France, cereal straw is the most common vegetal by-product, with the availability of $7 \mathrm{Mt} / \mathrm{y}$ [14]; therefore, a considerable number of studies have dealt with straw as an addition to the earth matrix. Among the 50 studies reviewed by Laborel-Préneron et al. [15], 17 studies concern straw incorporated in an earth matrix. However, most of these studies concentrate on mechanical [16-21] or thermal properties [22, 23]. Bouhicha et al. [9], using barley straw, looked at the durability along with the mechanical properties of earthen composite materials. Additionally, water shower tests were carried out to observe the impact of various straw treatments (water-repellent coatings).

The mechanical, thermal, and durability properties of hemp shiv in lightweight concrete applications have received attention recently [24-27], but its studies in an earth matrix are rare. Hamard et al. [28] focused on the case of an earth plaster with hemp chaff or sisal to study its mechanical properties, shrinkage, and bonding with the wall. Gomes et al. [29] characterized earth-based mortars containing one volume of clayish earth and three volumes of sand to repair rammed earth. The addition of hemp shiv (5\% wt. of the earth) decreased the linear and volumetric shrinkage and decelerated drying. However, after the drying test, it gave rise to undesirable biological growth, except upon the addition of air lime as a stabilizer. Flament et al. [30] studied the fresh state and mechanical properties of hemp-clay tiles. Another type of hemp shiv composite, having a sapropel matrix, was studied by Balciunas et al. [31]. The usual properties, such as thermal conductivity, compressive strength, acoustic insulation, or water vapor diffusion resistance factor, of these composites, were investigated, together with water absorption, which provided information about the durability with respect to different conditions, such as rain.

Portugal and France are two of the five main rice producers in Europe. With this industry, they produce rice husk, the protective coat of the grain. This agro-industrial by-product is often considered waste and is either burnt for its high calorific value to produce energy or mixed with the soil. Moreover, it is known to be rot-proof and resistant to insects. Adding unground rice husk into unfired earth composites has rarely been studied, although it has been investigated in several 
other building material applications, mainly to create lighter fired bricks that can improve thermal insulation [32-34] or in the form of ash in an unfired clay material [34]. Lightweight concrete with rice husk has also been explored in a few studies [35-38]. Chabannes et al. [35] developed a biobased concrete, in the same way as for hemp concrete, with a lime-based binder. The thermal and mechanical properties of rice husk concrete and hemp concrete are comparable. However, hempbased composites present a slightly better performance. An application of rice husk ash in unfired earth material was studied by Muntohar [39], who investigated the addition of rice husk ash and lime in compressed stabilized earth bricks. This addition enhanced the soil bearing capacity, with the optimal ratio of lime to rice husk ash being 1:1.

The present study explores some durability properties of bio-based earth products. The main focus of this paper is on several test procedures to assess the durability of unstabilized compressed earthen materials produced using vegetal waste. The durability depends on many parameters, environments, and types of degradation. Flammability is one critical aspect, while another is biological development. However, there is very limited information regarding earth building materials. One of the reasons is that the protection of the earth is achieved when a low natural fiber content is used [40, 41].

The major drawback of the earth materials is their poor water resistance, and hence, the aging and degradation of the organic material are not the main focus. Several recent reviews have focused on the assessment of their durability [42-44]. Beckett et al. [43] reviewed 60 articles about the durability of earthen materials. Ten different tests were considered in this review, which highlights the lack of universally accepted testing methodologies for testing the durability of earth materials. Most of the tests focus on water resistance, and shrinkage is also assessed as the cracks can create preferential seepage paths. As stated by Van Damme and Houben [45], an increasing number of researchers focus on the stabilized earth material to pass the severe tests available instead of adapting the architectural practice and developing new tests that are closer to real environmental conditions. Consequently, Medvey and Dobszay [42] reviewed exclusive papers on stabilized earth durability. They referenced three categories of tests: accelerated erosion tests, indirect tests, and outdoor natural weathering experiments. Cid-Falceto et al. [44] reviewed the international durability tests to assess the durability of compressed earth blocks against rain. The authors compared different spray and drip erosion tests according to different standards and technical documents. These tests were realized on earth blocks containing no plant aggregates, with some of them being stabilized by the addition of a binder.

Few specific standardized procedures currently exist in this regard, apart from the German Standard DIN 18945 [46] and the New-Zealand Standard 4298 [47]. The German Standard [46] presents three water resistance tests: the immersion test, the capillary absorption test, and the contact test. Similarly, the New-Zealand Standard also presents three water resistance tests: the wet/dry appraisal test, the erosion test by spraying, and the Geelong test; the latter being less aggressive was performed in this investigation. Some durability tests from the literature that could be used on unstabilized earthen materials were also used, such as low-pressure water absorption with Karsten tubes [10] or an impact resistance test using the Martinet-Baronnie apparatus [12]. Most of these tests should be conducted on the render applied on earth bricks-based masonry walls, as the outdoor parts of the walls are often coated with a render. However, the objective of this study is to discuss the relevance of some durability tests on the unstabilized earth material and compare the plant aggregates. In order to profit from the contribution of earthen materials to 
the indoor hygrothermal equilibrium, the indoor surface of the wall may not be plastered, and the earthen bricks are left exposed. In order to allow for a window to be left open when it rains and to support the daily cleaning activities, durability for water and usage is important. The focus will, hence, be on the earth bricks only. In this study, $3 \%$ weight content of barley straw, hemp shiv, and rice husk were incorporated into the earth composites to improve their durability properties. The influence of the type of plant aggregate on ultrasound velocity, dry abrasion resistance, water absorption under low-pressure, wet erosion resistance, and impact resistance was also analyzed.

\section{Materials and Methods}

\subsection{Raw Materials}

We used quarry fines from the washing aggregate sludge as earth, the reference material (RF). These fines are the waste formed by the washing of limestone aggregates produced for the concrete industry, where the sludge created is left to dry in the sedimentation basins. This waste is then reduced to powder and used later. The properties of the earth, determined in a previous study [48], are presented in Table 1.

Table 1 Physical and mineralogical properties of the earth and plant aggregates.

\begin{tabular}{|c|c|c|c|}
\hline \multicolumn{4}{|l|}{ Earth properties } \\
\hline \multicolumn{4}{|l|}{ Atterberg limits } \\
\hline $\mathrm{W}_{\mathrm{L}}(\%)$ & 30 & & \\
\hline$W_{P}(\%)$ & 21 & & \\
\hline $\mathrm{PI}(\%)$ & 9 & & \\
\hline $\mathrm{D} 50^{\mathrm{a}}(\mu \mathrm{m})$ & 6.5 & & \\
\hline \multicolumn{4}{|l|}{ Mineralogical composition } \\
\hline Calcite (\%) & 63 & & \\
\hline Dolomite (\%) & 3 & & \\
\hline Kaolinite (\%) & 11 & & \\
\hline Quartz (\%) & 10 & & \\
\hline Illite (\%) & 9 & & \\
\hline Goethite (\%) & 3 & & \\
\hline \multicolumn{4}{|l|}{ Plant aggregate properties } \\
\hline Material & Barley straw [49] & Hemp shiv [49] & Rice husk \\
\hline Bulk density $\left(\mathrm{kg} \cdot \mathrm{m}^{-3}\right)$ & $57.4 \pm 1.2$ & $153.0 \pm 2.4$ & $97.2 \pm 1.1$ \\
\hline Water absorption (\%) & $414 \pm 4$ & $380 \pm 11$ & $198 \pm 7$ \\
\hline $\operatorname{Diameter}^{\mathrm{b}}(\mathrm{mm})$ & $2.3 \pm 1.5$ & $2.0 \pm 1.2$ & $2.1 \pm 0.7$ \\
\hline Length $^{\mathrm{c}}(\mathrm{mm})$ & $7.6 \pm 4.4$ & $5.6 \pm 2.6$ & $7.9 \pm 1.6$ \\
\hline Thermal conductivity ${ }^{d}\left(W \cdot m^{-1} \cdot K^{-1}\right)$ & $0.044 \pm 0.001$ & $0.051 \pm 0.002$ & $0.047 \pm 0.001$ \\
\hline
\end{tabular}


We studied three plant aggregates in this work: barley straw, hemp shiv, and rice husk (Figure 1). Some of the physical properties of these plant aggregates are recapitulated in Table 1 . These three plant aggregates were studied for their availability and low thermal conductivity. Barley straw and hemp shiv were collected in France; their properties were determined in a previous study [49] on plant aggregates, coming from the same batch as the present study. The rice husk was collected in Portugal, and its properties were measured specifically for the present study using the procedures from the RILEM TC 236-BBM [50].
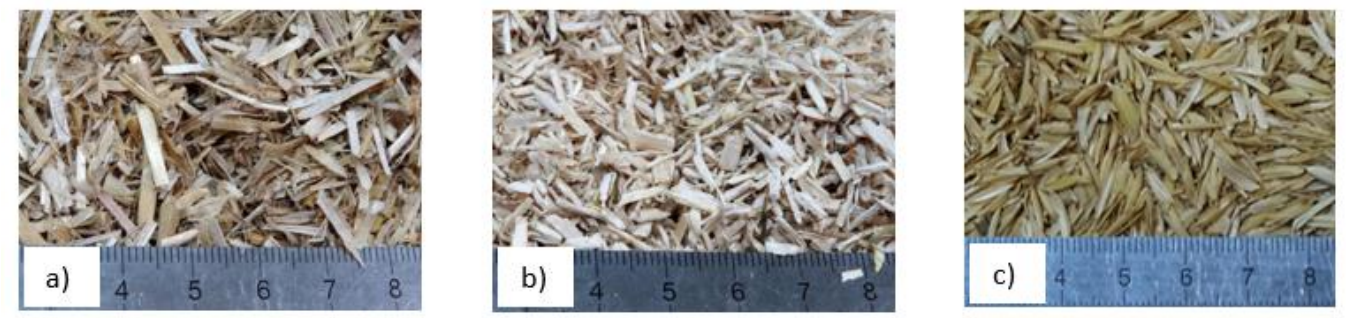

Figure 1 Pictures of plant aggregates: a) cut barley straw, b) cut hemp shiv, and c) rice husk.

\subsection{Earthen Specimen Production and Preliminary Characterization}

In order to perform various tests, the following four different composite formulations were prepared to be used as the testing specimens: one reference (RF), made with earth only, and three composites, each containing $3 \%$ by weight of one of the three plant aggregates. The $3 \%$ weight content of the plant aggregate, representing the ratio of the plant aggregates to the total dry mass (earth and plant aggregates), was chosen because it is possible to manufacture earthen bricks by extrusion up to this content, as proven in a previous study [51], which is useful in reducing the thermal conductivity and could be interesting for the industrialization of the process. However, their volume fraction was also calculated to facilitate the analysis of the results (Table 2). This volume content was calculated considering the density of the RF specimen and the density and mass proportion of plant aggregates for each composite. The optimum water content $\left(w_{\mathrm{opt}}\right)$ of the formulations was determined by the Proctor test, as described elsewhere [51]. In order to prepare these composites, the earth and plant aggregate fractions were poured into a blender and mixed by hand before adding water. The raw materials were mixed a day before molding.

Table 2 Proportions and water content, density, compressive strength, and thermal conductivity of the composites.

\begin{tabular}{lllll}
\hline Formulation & RF & B & H & R \\
Plant aggregate & - & Barley straw & Hemp shiv & Rice husk \\
\hline Weight fraction (\%) & 0 & 3 & 3 & 3 \\
Volume fraction (\%) & 0 & 26 & 22 & 14 \\
W $_{\text {opt }}(\%)$ & 14 & 19 & 17 & 17 \\
$\rho_{d}\left(\mathrm{~kg} \cdot \mathrm{m}^{-3}\right)$ & $1995 \pm 0$ & $1519 \pm 1$ & $1603 \pm 57$ & $1769 \pm 21$ \\
$\sigma_{\mathrm{c}}(\mathrm{MPa})$ & $4.0 \pm 0.4$ & $3.3 \pm 0.2$ & $2.4 \pm 0.2$ & $3.1 \pm 0.1$ \\
\hline
\end{tabular}




\begin{tabular}{lllll}
\hline$\lambda\left(\mathrm{W} . \mathrm{m}^{-1} \cdot \mathrm{K}^{-1}\right)$ & $1.1 \pm 0.04$ & $0.36 \pm 0.02$ & $0.45 \pm 0.02$ & $0.60 \pm 0.05$
\end{tabular}

We manufactured rectangular prismatic specimens with dimensions $150 \mathrm{~mm} \times 150 \mathrm{~mm} \times 50$ $\mathrm{mm}$, and cylindrical specimens $5 \mathrm{~cm}$ in diameter and $5 \mathrm{~cm}$ high by static compression at the Proctor density. The cylindrical specimens were made only for the compressive strength tests.

The specimens were first dried at $40^{\circ} \mathrm{C}$ for $24 \mathrm{~h}$; the temperature was then increased slowly to $100{ }^{\circ} \mathrm{C}$ and maintained at $100{ }^{\circ} \mathrm{C}$ until the weight remained constant (weight variation less than $0.1 \%$ between two weighing measurements $24 \mathrm{~h}$ apart). This rise in temperature, although potentially leading to a transformation of the material microstructure, was inspired by the industrial process of drying bricks before firing them. The specimens were stored in a room at $20{ }^{\circ} \mathrm{C}$ and $65 \%$ relative humidity $(\mathrm{RH})$ and were tested from the moment they were in equilibrium with the environment (about one week later). Table 2 recapitulates the various proportions (weight and volume fractions in \%), and properties of the specimens studied. We measured the density of the specimens by the quotient of the sample mass by its volume. The mass was assessed with a scale of $10^{-2} \mathrm{~g}$ precision, and the volume was assessed using a digital caliper with $10^{-4} \mathrm{~m}$ precision [50]. Their compressive strength was assessed on cylindrical specimens, $5 \mathrm{~cm}$ high and $5 \mathrm{~cm}$ in diameter, as described in a previous study [50], using a $100 \mathrm{kN}$-capacity hydraulic press, by applying a load at a constant deflection rate of $3 \mathrm{~mm} \cdot \mathrm{min}^{-1}$, with the specimens in direct contact with the steel plates. We tested the thermal conductivity with a heat transfer analyzer (Isomet 2104) and a 60-mm-diameter API 210412 contact probe. The tests were done in sets of three.

The volume proportions differed between barley straw (26\%), hemp shiv (22\%), and rice husk (14\%) because of the different types of bioaggregates with different loose bulk densities. Rice husks are like a shell. These volume fractions are not proportional to the respective bulk densities of the plant particles (Table 1), a feature that might be linked to their different compressibility. Bulk density $\left(\rho_{d}\right)$ and compressive strength $\left(\sigma_{c}\right)$ of RF, B, and $H$ specimens were measured in a previous study [51] while the values for $R$ specimens are new. The compressive strength of $R F$ specimens was the highest, followed by $B, R$, and finally, $H$ specimens. The lower the dry density of the composites, the lower was their thermal conductivity.

\subsection{Ultrasound Velocity}

This non-destructive technology is helpful in estimating several characteristics of a material, such as homogeneity, dynamic elastic modulus, and presence of cracks. This test is interesting in the durability approach as it characterizes some degradation inside the material. For example, ultrasound velocity measurements were used by Barbera et al. [52] to assess the durability of the stone, specifically during accelerated aging tests. This approach had already been used by Aubert and Gasc-Barbier [53] to evaluate the effects of freezing-thawing cycles on clayey soil bricks.

We obtained ultrasound velocity using a Pundit Lab-Proceq device and tested three times for each of the three specimens of the same type. The measurements were performed by a direct method, meaning that the two probes (transmitter and receiver) were facing each other on either side of the specimen. Eight measurements were carried out on each specimen, four for each direction under consideration (perpendicular to side A and side B), as presented in Figure 2 . Toothpaste, a viscoelastic material, was used to ensure fine contacts between the transducers and the specimen. The device gave the time of propagation, and the velocity was deduced from this 
value and also the distance between the transducers. The dynamic modulus can be calculated from the following equation (1):

$$
E=\frac{\rho V^{2}(1+v)(1-2 v)}{(1-v)} \#(1)
$$

where $\rho$ is the density in $\mathrm{kg} \cdot \mathrm{m}^{-3}, \mathrm{~V}$ is the ultrasound velocity in $\mathrm{m} \cdot \mathrm{s}^{-1}$, and $\mathrm{v}$ is the Poisson's coefficient. However, Poisson's coefficient was not measured in this study because of its unknown correct value. The findings were thus discussed only concerning the ultrasound velocity linked with the porosity or the dry density of the material.

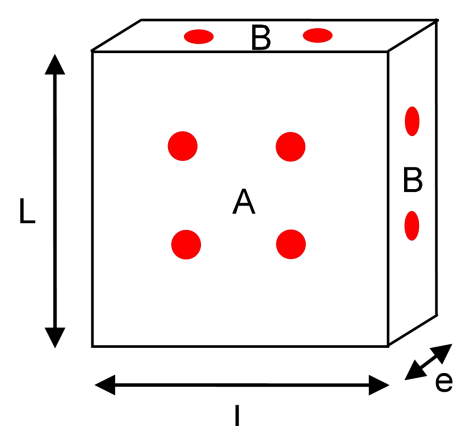

Figure 2 Positioning of test points for ultrasound velocity test.

\subsection{Dry Abrasion Resistance}

This test was carried out on different earth-building elements, such as plasters [10], bricks [12, 54], or bahareque (a technique similar to wattle and daub) [55]. It helps assess the surface resistance to mechanical erosion due to the repetitive friction of the occupants' activities or to solid particles blown by the wind.

We evaluated the dry abrasion resistance according to the German Standard DIN 18947 [56] for unstabilized plastering mortars by measuring the quantity of material removed from the specimens after 20 rotations with a hard plastic brush. A 65-mm diameter brush was pressed against the surface of the specimen by a mass of $2 \mathrm{~kg}$ (Figure 3 ). Three tests were performed on each of the three specimens per formulation. The coefficient of abrasion in $\mathrm{g}_{\mathrm{cm}} \mathrm{cm}^{-2}$ was then calculated with equation (2), according to Millogo et al. [54]:

$$
C_{a}=\frac{m_{1}-m_{2}}{S} \#(2)
$$

where $m_{1}$ and $m_{2}$ are the masses before and after brushing in $g$, and $S$ is the brushed area in $\mathrm{cm}^{2}$. 


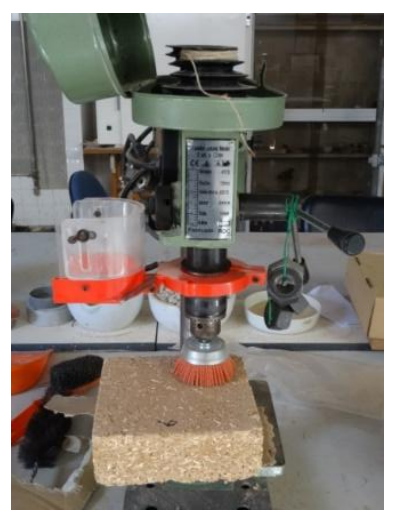

Figure 3 Dry abrasion test.

\subsection{Low-pressure Water Absorption}

We performed this test to measure the water absorption of a porous wall under low pressure, which was taken to simulate the action of rain combined with wind. The Karsten tube penetration test [57] was performed using a glass tube filled with water and sealed to the specimen with water-resistant plasticine (see Figure 4). The tube was graded to measure the volume of water that penetrated the material, and the time of absorption was measured (EN 16302 [58]). Vertical tubes were sealed on the horizontal surface of the specimens because it is easier than sealing them on the vertical surfaces of the materials under investigation. Two measurements were done at different points for each of the three specimens tested per formulation.

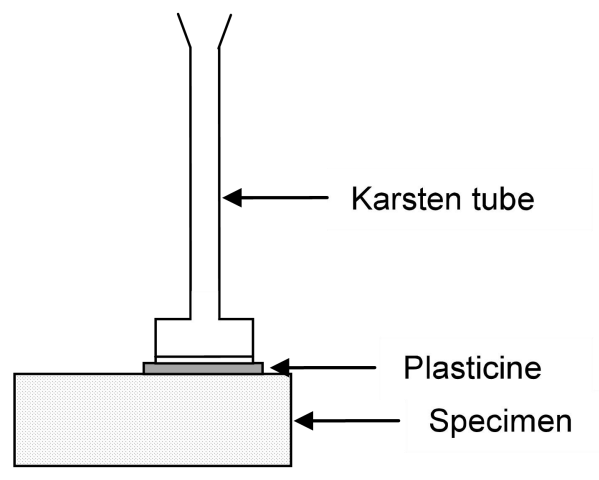

Figure 4 Schematic representation of the test of water absorption under low pressure.

The absorption times were different according to the mixture tested. It was, thus, chosen to measure the time taken for each $0.5 \mathrm{~mL}$ of water to be absorbed for the graphic representation of the results. The water absorption coefficient $\left(C_{A}\right.$ in $\left.\mathrm{g} \cdot \mathrm{m}^{-2} \cdot \mathrm{s}^{-1}\right)$ was also calculated between the water uptake of $3 \mathrm{~mL}$ and $2 \mathrm{~mL}$ according to equation (3):

$$
C_{A}=\frac{m_{3 m l}-m_{2 m l}}{A \times\left(t_{3 m l}-t_{2 m l}\right)} \#(3)
$$

where $\mathrm{m}_{3} \mathrm{~mL}$ and $\mathrm{m}_{2} \mathrm{~mL}$ are the masses corresponding to the water uptake of $3 \mathrm{~mL}$ and $2 \mathrm{ml}$, respectively, $A$ is the contact area between the Karsten tube and the earthen specimens in $\mathrm{m}^{2}$, and $t_{3 \mathrm{~mL}}$ and $t_{2} \mathrm{~mL}$ are the times in s corresponding to the water uptake of $3 \mathrm{~mL}$ and $2 \mathrm{~mL}$, respectively. 
This equation was adapted from Stazi et al. [59] and Hendrickx [60], where the difference in water absorption between $15 \mathrm{~min}$ and $5 \mathrm{~min}$ was used. For different materials, the period for the water to be absorbed is too broad to use these original equations.

\subsection{Wet Erosion Resistance}

We performed the wet erosion test to simulate rain or accidental water droplets when the unstabilized earth composites are unprotected outdoors or used indoors in contact with liquid water. This test was first studied by Cid-Falceto et al. [44], who concluded that it was more suitable for unstabilized compressed earth bricks than the water spray tests. The test was carried out according to the New-Zealand Standard NZS 4298 [47], intended for unstabilized adobes, possibly containing straw and pressed bricks, based on the Geelong method. A volume of $100 \mathrm{~mL}$ of water was allowed to drip from a height of $400 \mathrm{~mm}$ onto the specimen inclined at $27^{\circ}$ (see Figure 5). We tested four specimens per formulation. The duration of the test ranged between 15 to $25 \mathrm{~min}$ (adapted from the standard, from 20 to $60 \mathrm{~min}$ ). The pit depth was measured with a digital caliper. The erodibility index, between 3 and 5 (fail), was deduced from this value according to NZS 4298 [47]. A material with a pit depth between 5 and $10 \mathrm{~mm}$ and erosion class 3 was considered as erosive. With a pit depth between 10 and $15 \mathrm{~mm}$ corresponding to class 4 , the material was considered very erosive. Finally, if the pit depth exceeded $15 \mathrm{~mm}$, the class was 5 , and the material was considered to have failed the test.

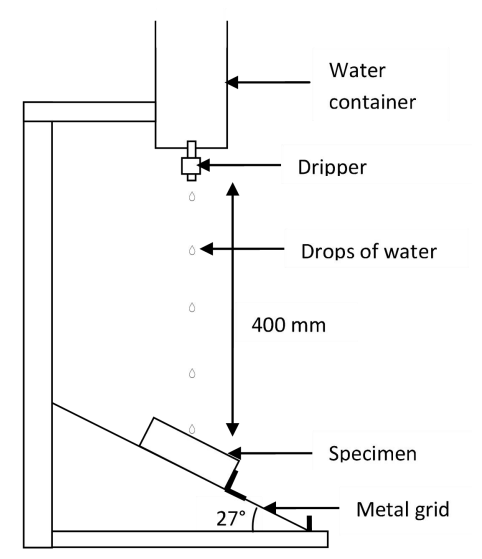

Figure 5 Schematic representation of the Geelong water drop erosion test (based on NZS 4298 [47])

\subsection{Sphere Impact Test}

The walls of buildings may be subjected to different kinds of stimuli, such as a stone thrown at the wall or some impulse by people or furniture. In this study, to evaluate the resistance to such stimuli, the Martinet-Baronnie impact apparatus was used, and the test was carried out on the specimens that had already been tested by all the previous methods (ultrasound, thermal conductivity, dry abrasion, erosion, and low-pressure absorption). As a representative, this test should be realized on a real scale material: full brick for a load-bearing wall or with render applied on a substrate or thin material in case of a partition wall (current case). This test was inspired by 
ISO 7892 with a small hard impact body [61], currently used for testing External Thermal Insulation Composite Systems (ETICS) following EN 13497 [62] as well as for renders [63, 64]. The test device consisted of a spherical metallic mass of $500 \mathrm{~g}$ on a metallic stalk that was attached to the wall. It was dropped from the horizontal position onto the specimen located vertically underneath (Figure 6 ), in contact with a very rigid wall. The energy generated by the test was 3 joules. The number of impacts was between 1 and 4, depending on the impact resistance (formed cracks). The test was conducted on four specimens of each composition as it was very quick and easy to perform. The properties of the specimens found after the test provided interesting qualitative information. The diameter of the visible impact area was measured with a digital caliper, and the cracking and general behavior of the specimens were assessed.

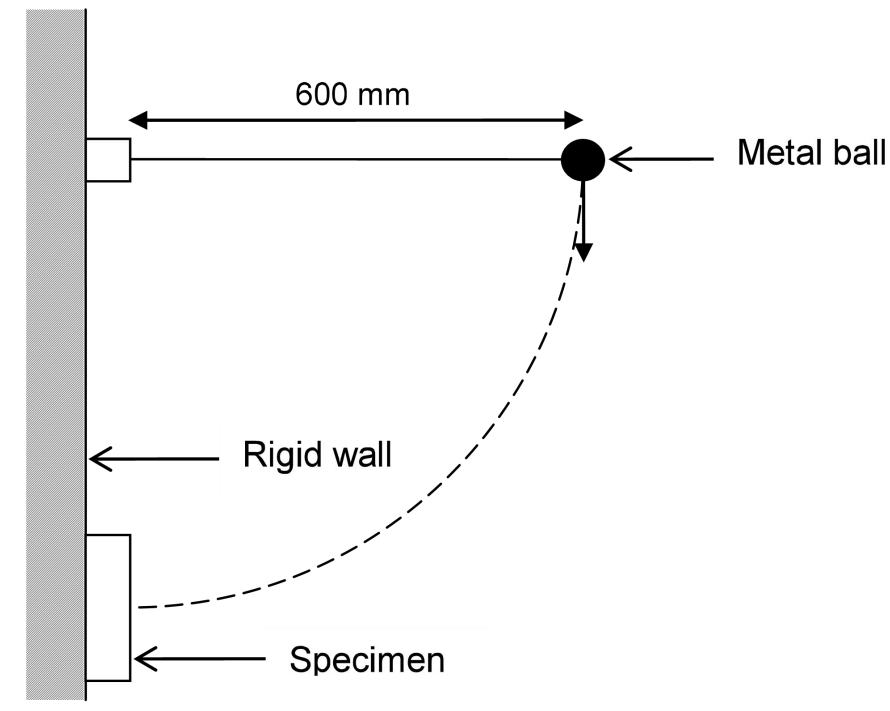

Figure 6 Schematic representation of the impact resistance test.

\section{Results}

\subsection{Ultrasound Velocity}

The time of ultrasound propagation was measured in 2 directions of the prismatic specimens; the ultrasound velocity values are presented in Figure 7.

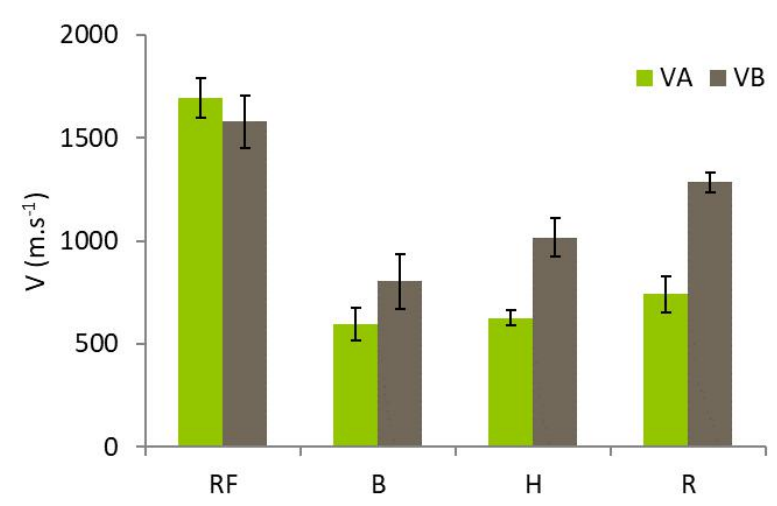

Figure 7 Ultrasound velocity of the composites according to the two directions A and B. 
The velocity differed slightly with the direction of propagation: perpendicular to the molding pressure (side $A$ ) or parallel to the molding pressure (side $B$ ) (Figure 7 ). In the case of $B, H$, and $R$ results, the ultrasound velocity was higher. The ultrasound velocity decreased with the addition of plant aggregates compared to the reference material. This decrease was due to the increase in porosity and, thus, a decrease in the mechanical strength [65]. It is not only an indirect quantification of their cracking and porous structure but also external. Compared to the RF specimen, the decrease in velocity measured between sides $A$ and $B$ in specimens $B, H$, and $R$ was $65 \%, 63 \%$, and $56 \%$, respectively. Thus, the ultrasound velocity decreased with density and an increase in the volume fraction of the plant aggregates. For the RF specimens, velocity was higher than that of the rammed earth, as studied by Faria et al. [66]; it was $928 \mathrm{~m} . \mathrm{s}^{-1}$, although the specimens with plant aggregates presented velocities closer to that of the lime-earth render, as studied in Faria's paper [66] (between 551 and $775 \mathrm{~m} . \mathrm{s}^{-1}$ ). Comparing the VA velocity of the R compacted composite with gypsum, and air lime stabilized casted one using earth and rice husk [38], a similar value of approximately $750 \mathrm{~m} . \mathrm{s}^{-1}$ was achieved for the casted composites with $15 \%$ volume of rice husk. Although these uncompressed stabilized earth-rice composites presented a density of $1022 \mathrm{~kg} \cdot \mathrm{m}^{-3}$, much lower in comparison to the compressed ones in the present study (Table 2), a similar performance of rice-earth composites, in terms of ultrasound velocity, was achieved probably due to the balance between the composition and production technology. The addition of a binder may have densified the earthen matrix of cast rice husk specimens (with high rice husk volume), while in the present study, the compaction of unstabilized ones may have densified the composites. Based on a study by Brás et al. [67], the length and orientation of the bio-sources (which also depend on the composites being just cast or compressed) could also have influenced the ultrasound propagation velocity results.

\subsection{Dry Abrasion Resistance}

The results of abrasion are shown in Figure 8. It was found that the smaller the coefficient of erosion, the higher was the dry abrasion resistance of the composite.

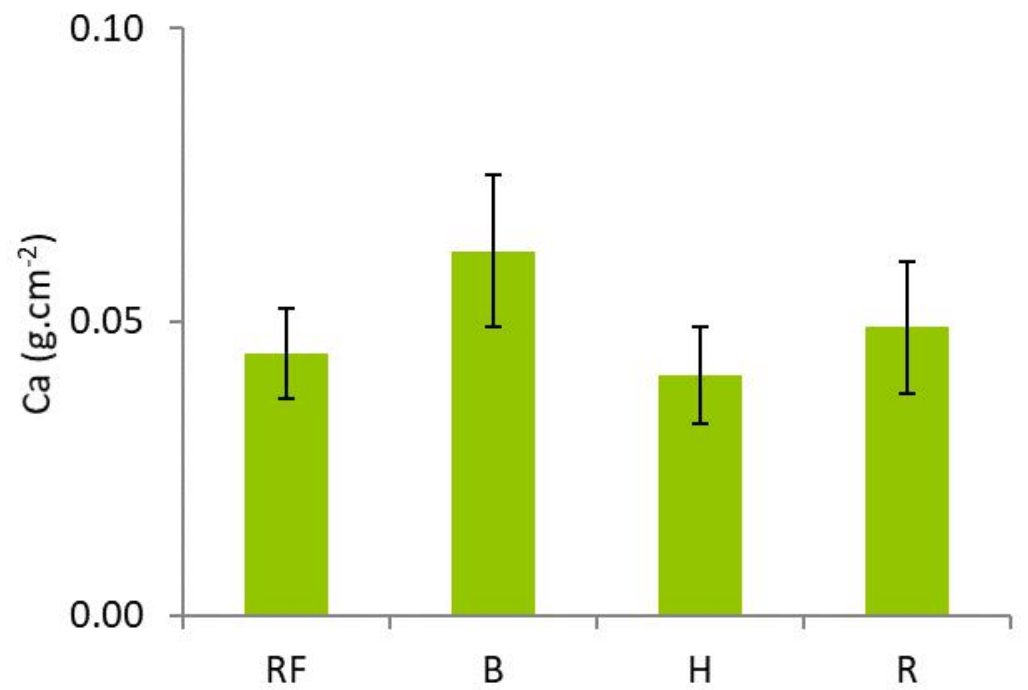

Figure 8 Dry abrasion coefficient of the composites. 
$\mathrm{H}$ and RF were the mixtures with the lowest abrasion coefficient $\left(0.04 \pm 0.01 \mathrm{~g} . \mathrm{cm}^{-2}\right)$, followed by $R$ with $0.05 \pm 0.01 \mathrm{~g} . \mathrm{cm}^{-2}$ and $B$ with $0.06 \pm 0.01 \mathrm{~g} . \mathrm{cm}^{-2}$. Considering the standard deviations, the differences in the dry abrasion resistances among the various formulations were not particularly marked. The high abrasion coefficient of B could be because of the length of the straw particles, which are longer than hemp shiv and closer in length to rice husks but with a higher discrepancy, thus allow more earth to be removed.

Usually, the abrasion results for different mixtures are compared according to the quantity of earth removed during the test $[55,68]$, and the material is classified according to the standard [56]; however, this applies only to the case of mortars. Here, it was chosen to express the result as a coefficient, depending on the surface under test, to compare the results with others from the literature. The values obtained in this study were slightly higher than those from the study by Millogo et al. [54] for pressed adobe blocks and lie between 0.015 and $0.04 \mathrm{~g} . \mathrm{cm}^{-2}$. However, their maximum fiber content was $0.8 \%$ by weight, which explains the difference. Moreover, it is important to note that the abrasion coefficients can also be influenced by the hardness of the brush, which makes it difficult to compare the results from different laboratories [68]. Using the same brush and test, Antunes et al. [38] found a much higher abrasion coefficient $\left(0.125 \mathrm{~g} . \mathrm{cm}^{-2}\right)$ for gypsum and air lime stabilized uncompressed earth-rice composites. This difference shows the impact that the lower content on rice husk ( $9 \%$ instead of $15 \%$, in volume) and the compression may have on the bio-sourced earthen composites, which compensates the effect of stabilization, providing alternatives for unstabilized composites.

\subsection{Low-pressure Water Absorption}

The results of the low-pressure absorption test are presented in Figure 9; the graph shows the water absorbed per unit of surface $\left(\mathrm{ml} . \mathrm{mm}^{-2}\right)$ as a function of time ( $\left.\mathrm{min}\right)$.

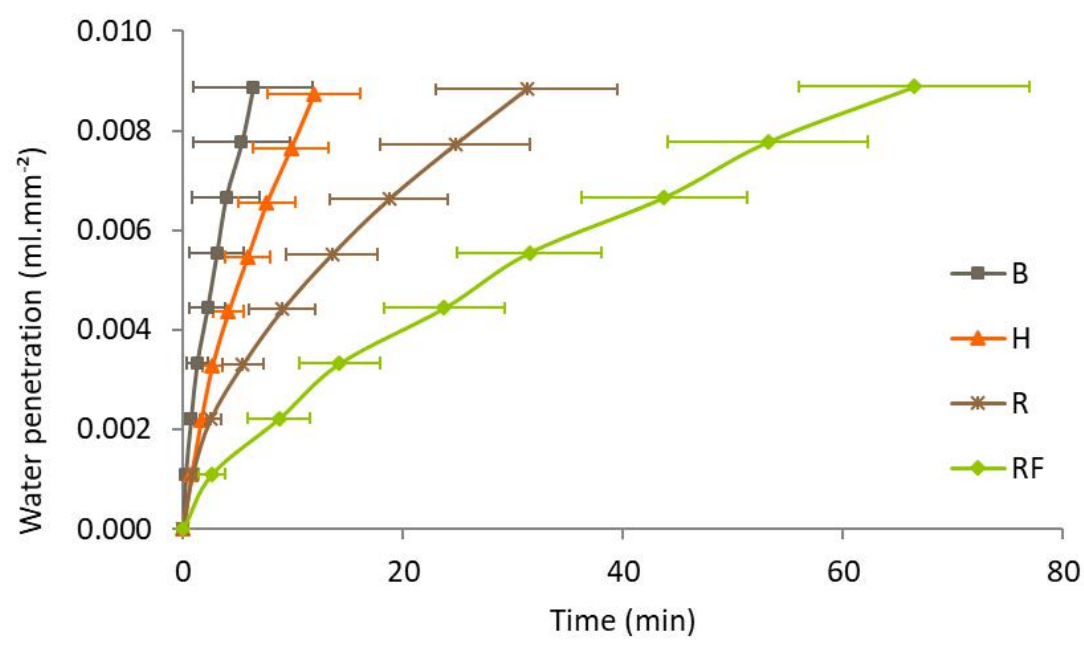

Figure 9 Low-pressure water absorption curves of the composites.

The first striking result of this test was that the absorption velocities were very different according to the materials tested. The time required to absorb the same volume of water was much shorter for bio-sourced composites than that for the earth-alone specimens. The total 
amount of water, $4 \mathrm{ml}$, was absorbed in $6.4 \pm 5.4,11.9 \pm 4.2,31.2 \pm 8.3$, and $66.5 \pm 10.5 \mathrm{~min}$ for $\mathrm{B}, \mathrm{H}$, $\mathrm{R}$, and RF specimens, respectively.

The increase in the absorption rate or liquid water permeability of the bio-sourced composites is due to the presence of the plant aggregates and their high absorption capacity [55]. The interfacial zone between the earth matrix and the plant aggregate may also be an important reason. The absorption rate, expressed by the absorption coefficient $C_{A}$, varied considerably among the specimen formulations (Table 3): from $1.85 \mathrm{~g} \cdot \mathrm{m}^{-2} \cdot \mathrm{s}^{-1}$ for RF specimens to $21.98 \mathrm{~g} \cdot \mathrm{m}^{-2} \cdot \mathrm{s}^{-}$ ${ }^{1}$ for $B$ composites. The $C_{A}$ can then be generally related to the density of the composite (Table 2 ). The lower the density of the composite, the higher is its water absorption capacity. With a water absorption coefficient of $3.82 \mathrm{~g} \cdot \mathrm{m}^{-2} \cdot \mathrm{s}^{-1}$, $\mathrm{R}$ is an earthen composite with plant aggregates that is the most interesting in terms of resistance to liquid water ingress. Its coefficient is quite close to that of RF, $1.85 \mathrm{~g} \cdot \mathrm{m}^{-2} \cdot \mathrm{s}^{-1}$, and can be explained by the lower volume content of the plant aggregates than that in $\mathrm{B}$ or $\mathrm{H}$ specimens for the same weight content (Table 2).

Table 3 Low-pressure water absorption coefficient $C_{A}$ for each composite.

\begin{tabular}{ll}
\hline References & $\mathrm{C}_{\mathrm{A}}\left(\mathrm{g} \cdot \mathrm{m}^{-2} \cdot \mathrm{s}^{-1}\right)$ \\
\hline $\mathrm{RF}$ & 1.85 \\
$\mathrm{~B}$ & 21.98 \\
$\mathrm{H}$ & 10.44 \\
$\mathrm{R}$ & 3.82 \\
\hline
\end{tabular}

These results are comparable with some absorption coefficients obtained by Stazi et al. [59]. A water absorption coefficient of $2.33 \mathrm{~g} \cdot \mathrm{m}^{-2} \cdot \mathrm{s}^{-1}$ was obtained for a basic plaster with barley straw, and a value of $0.50 \mathrm{~g} \cdot \mathrm{m}^{-2} \cdot \mathrm{s}^{-1}$ was obtained for a rammed earth wall. Nevertheless, in that study, the barley straw content was much lower than the $3 \%$ by mass used for plant aggregates in the present study, which explains the big difference between the absorption rates of this plaster and that of the $\mathrm{B}$ composites. The absorption rate of the RF specimens is quite close to that of the basic plaster found by Stazi et al. [59]; some differences may be due to the difference in clay content and type. High clay content can reduce liquid water permeability [59]. Moreover, the type of clay may influence the water permeability. Another comparison can be made with a study by Faria et al. [66]; the absorption observed in the present study for the rammed earth is lower than that observed by Faria's study, which shows the absorption of around $15 \mathrm{~mL}$ of water in $5 \mathrm{~min}$. Here, the maximum absorption for B was $4 \mathrm{~mL}$ in $6 \mathrm{~min}$. However, the tests were performed with the Karsten tubes applied horizontally in the present study and vertically in the study by Faria et al. [66], which may also have introduced the differences.

At the end of the test, each part of the composites in direct contact with water had taken a plastic state. This behavior, expected because of the characteristics of chemically unstabilized clay, has been already observed by Mattone et al. [55], from the sixth minute, in a similar test.

\subsection{Wet Erosion Resistance}

The results of the erosion test are presented in Figure 10. 


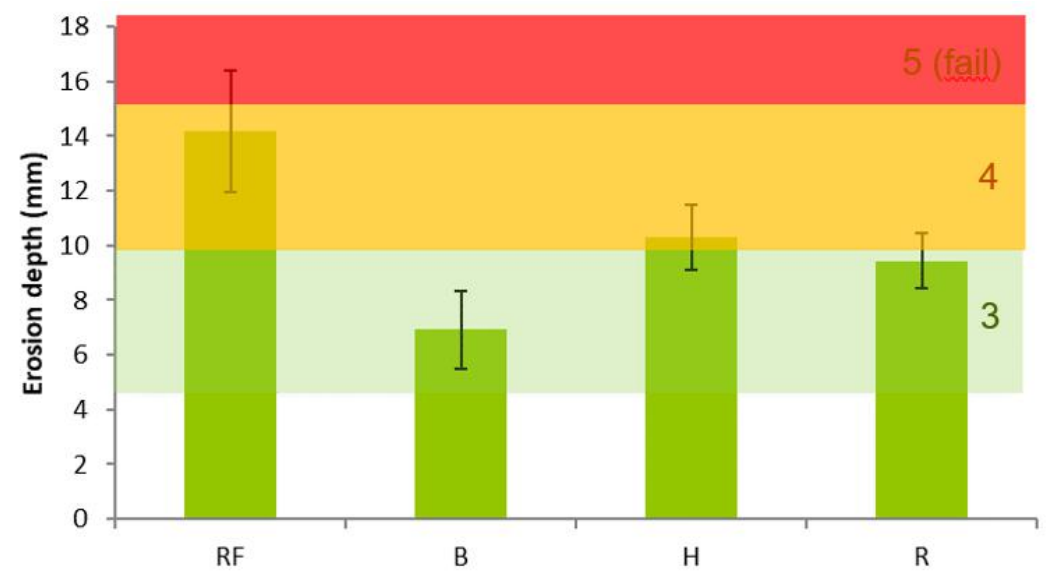

Figure 10 Erosion depth of the composites after the Geelong test.

The erosion depth for each type of specimen is presented in Figure 10, and the erodibility index is added to see the class of erosion of the composites directly. The least erosive composite was $B$, with a pit depth of $6.9 \pm 1.4 \mathrm{~mm}$, followed by $\mathrm{R}$ with $9.4 \pm 0.9 \mathrm{~mm}, \mathrm{H}$ with $10.3 \pm 1.2 \mathrm{~mm}$, and RF with $14.2 \pm 2.2 \mathrm{~mm}$. According to the erodibility index, B and R specimens belonged to class 3, i.e., they are erosive according to Frencham [69] (cited by Heathcote [70]), and $\mathrm{H}$ and RF specimens belonged to class 4, i.e., they are very erosive. According to the New Zealand standard [47], these formulations are suitable for adobe bricks for building constructions.

For each test performed, the water that dripped was absorbed by the composites. Higher resistance upon addition of plant aggregates was also observed by Ashour and Wu [71] with barley straw, wheat straw, and wood shavings. According to Ashour and $\mathrm{Wu}$ [71], the improvement of the resistance could be attributed to the uniform distribution of water among the particles. The erosion depth was also measured by Bui et al. [72] on the walls exposed to weather and by CidFalceto et al. [44] with a similar test on the bricks. In both studies, for the unstabilized earth walls and bricks, the average depth of erosion was around $6 \mathrm{~mm}$. This value is lower than the values observed in this study. However, in the first study, it was explored in the south-east of France, where rainfall is low, and in the second study, the test lasted for only 10 min, which clarifies the better performance.

This test is, however, appropriate if the rainfall is less than $500 \mathrm{~mm}$ per year [70]. In France, the rainfall is between 800 and $900 \mathrm{~mm}$ per year on average, which is considerably higher. In such a case, Frencham [69] recommends considering the category of erosion to be one or two classes higher. A protective coating can also be envisioned.

\subsection{Sphere Impact Test}

The impact diameters of the specimens tested are presented in Figure 11. The pictures of the specimens after the test are shown in Figure 12. The occurrence of cracking observed visually denotes lower deformability, the value of which is negative, while the capacity to recover shape indicates resilience, which in turn has a very positive value. 


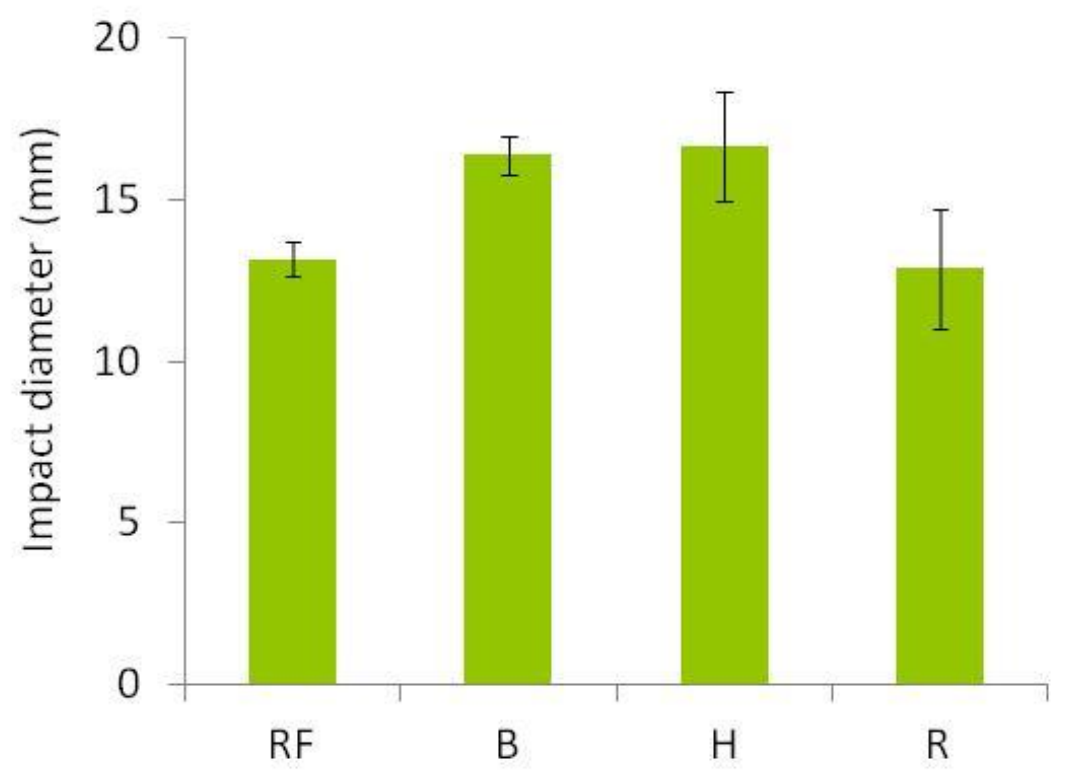

Figure 11 Impact diameter of the composites.
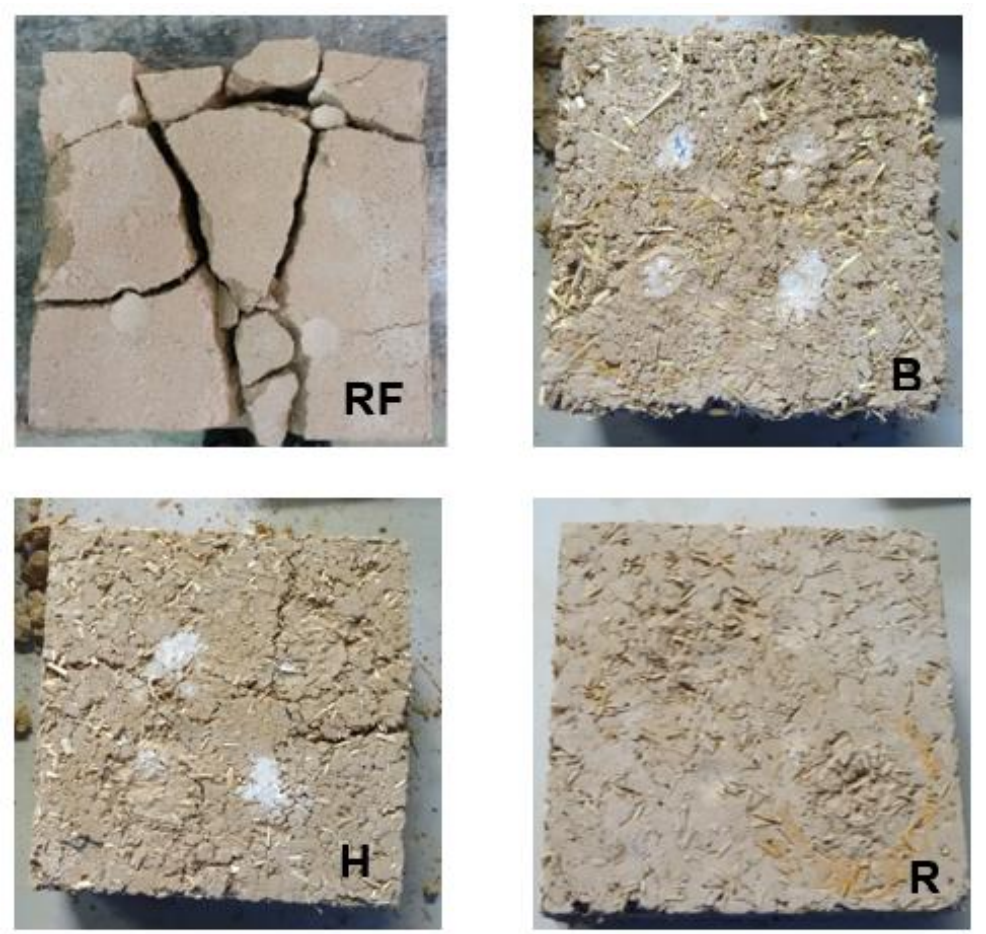

Figure 12 Different specimens after the sphere impact test.

As can be seen in Figure 11, the impact diameters were $13.2 \pm 0.5,16.4 \pm 0.6,16.7 \pm 1.7$, and $12.9 \pm 1.8 \mathrm{~mm}$ for RF, B, H, and R specimens, respectively. R composites, with the lowest impact diameter, were the most resistant material with some deformability: there were no cracks, even after 3 or 4 impacts on the same specimen. B specimens had the second-highest diameter, but the impact was hardly discernible, and there were only small cracks, except for a bigger one in one specimen. $\mathrm{H}$ specimens showed a huge contrast in behavior after the impact: one specimen was totally broken, another one had a big crack, and the last one had only a small crack. The worst 
resistance was shown by the RF specimens, which were very brittle, and every specimen was cracked or broken after the first and the only impact. Thus, the effect of the plant fibers can be differentiated clearly in Figure 12.

\section{Discussion}

Three plant aggregates were tested as the components of earth composites: barley straw, hemp shiv, and rice husk. Their influence on the ultrasound velocity and durability properties was studied. The main results are presented in a radar chart (Figure 13) that indicates the most interesting (100\%) formulation and the least advantageous (0\%) formulation, according to a certain property: ultrasound velocity, dry abrasion, water absorption, erosion depth, or impact resistance. The intermediate outcome, calculated in percentage, is proportional to the best and the worst value. For the impact behavior, the values were arbitrary, depending only on the material behavior and not on the diameter of the impact. Material behavior, after an impact, is undoubtedly the most defining factor when considering a building material. The comparison between the formulations is based on the same weight content of $3 \%$ as it is easily available and facilitates fabrication, although the different properties are more likely to be related to the volume fraction of the plant aggregates in the material.

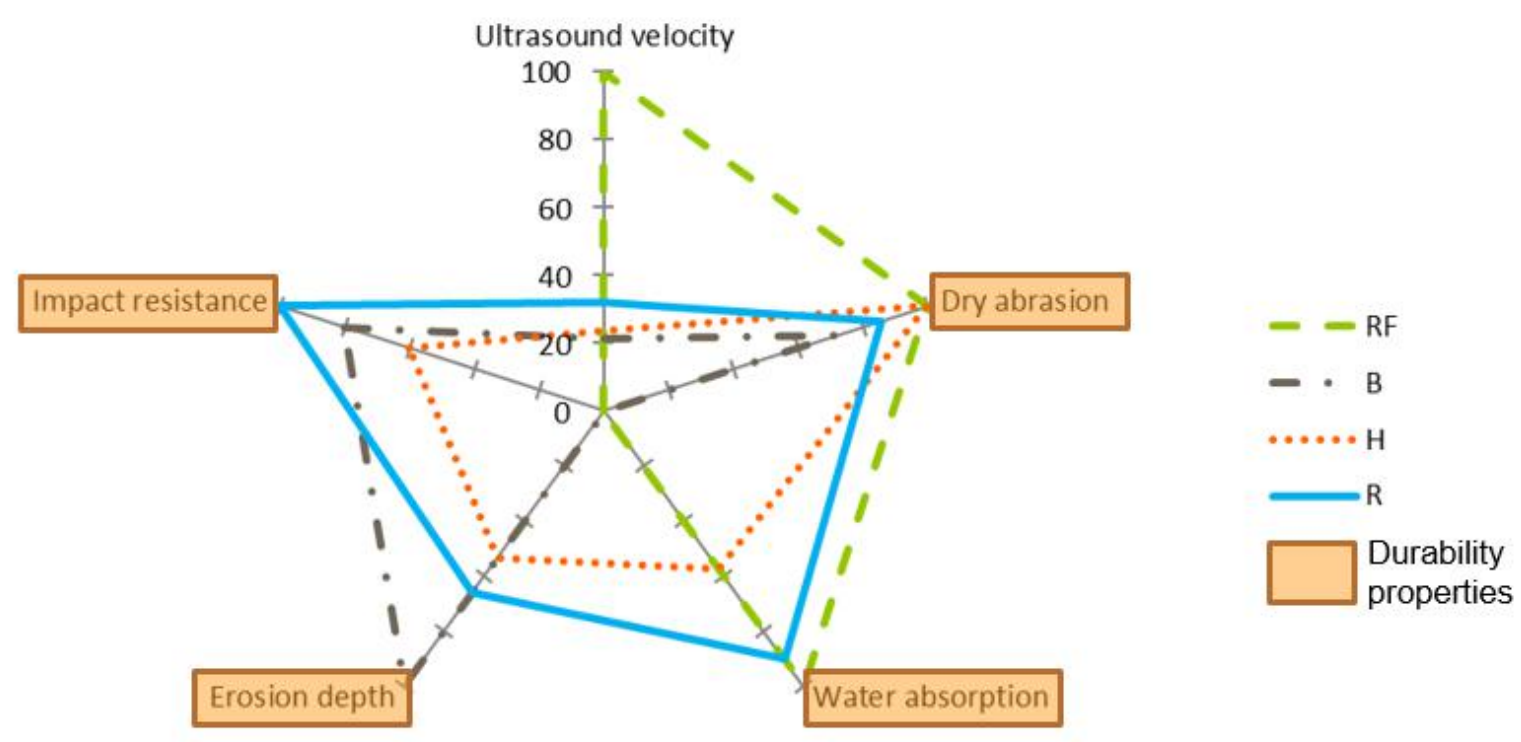

Figure 13 Diagram qualitatively comparing the various composites according to the property.

The properties presented in the chart can be distinguished as follows: ultrasound velocity represents usefulness, whereas the other four are durability properties.

Choosing one formulation over another requires a compromise among the different properties and should also consider the place of application of the unstabilized earthen composites, i.e., more exposed or more protected locations. The merits and demerits of the different composite formulations tested in this work are summarized below.

- Composites without plant aggregates (RF) present the highest ultrasound velocity or stiffness, but this property leads to very low impact resistance; the specimens are easily breakable. 
This formulation is best for water absorption resistance (Karsten tubes) and dry abrasion resistance (equal to $\mathrm{H}$ specimens). However, it should be noted that the dry abrasion results were very close to each other for all the materials (bearing in mind that Figure 13 does not take the uncertainties into account). The RF specimens are the least resistant to erosion (Geelong test).

- Composites with barley straw (B) are resistant to erosion and impact. Their dry abrasion resistance was less than that of $\mathrm{RF}, \mathrm{H}$, and $\mathrm{R}$ but still competitive. Moreover, their stiffness and water absorption resistance values are very low.

- Composites with hemp shiv $(\mathrm{H})$ present a behavior quite similar to that of $\mathrm{B}$, with a slightly better dry abrasion resistance and better resistance to water absorption but lower resistance to erosion.

- Composites with rice husk (R) present the best behavior. These are very good with respect to the durability property, although the stiffness is much lower than that of the specimens made of earth alone. The stiffness of $\mathrm{R}$ was, however, the highest of the composites with plant aggregates.

The relevance of some tests can also be discussed. The Karsten tubes would determine durability against rainfall if the test is performed on a vertical specimen (equivalent to an exposed wall, which is not the common case for unstabilized earthen composites). However, the conditions of this test can include the case of a window left open and the rainwater coming in contact with a surface. Moreover, the tube with the specimen is delicate to seal, particularly with the specimens containing plant aggregates. The ultrasound velocity test used to evaluate the stiffness or the damage caused by freezing-thawing cycles, in some studies, is easy to perform and has the advantage of being non-destructive. However, no correlation could be found between the measured velocity and the durability properties from the present investigation.

The drawbacks of the test can be noted as follows. The analysis of the results of the impact resistance test is not fully reliable. The impact diameter, quite difficult to measure, is not sufficient to describe the behavior after impact. The impact behavior itself is very subjective. Nevertheless, this test can simulate the impact of furniture used indoors on the unplastered earthen composite masonry. Concerning the dry abrasion resistance, the test is quite useful for comparing results within one study, but it becomes complicated to obtain a real value for comparison with those of other studies. Nevertheless, this test can simulate abrasion by building users indoors when in contact with an unplastered earthen composite masonry. As mentioned in the results section, the material removed during the test depends on the hardness of the brush used. Nonetheless, impact resistance, dry abrasion, and erosion resistance tests are representative of the real potential conditions. Here, only the wet erosion resistance is compared to the thresholds. This threshold is, however, not adapted to all local climates. The comparison between the thresholds should be assessed once relevant and standardized tests are universally accepted and would be representative of natural aging. The thresholds would then be determined according to the test, environmental conditions, geography, and use of the material (load-bearing or not, plastered/rendered or not, indoor/outdoor).

\section{Conclusions}

The present study focuses on some durability properties of the earthen composites containing one of the following plant aggregates: barley straw, hemp shiv, or rice husk. 
The first objective was to characterize the influence, on some durability properties, of adding these three types of plant aggregates in an earth construction material. The main findings are summarized here. The addition of these bioaggregates decreased the stiffness, estimated by ultrasound velocity, up to $53 \%$, in the case of specimens with barley straw. It improved resistance to impact, particularly with the addition of rice husk and barley straw, and also improved resistance to erosion by water, from class 4 to class 3 , in the case of rice husk and barley straw. However, these vegetal additions led to an increase of water absorption, under low pressure, due to the high hygroscopicity of the plant matter and to a slight decrease of the dry abrasion resistance. From the durability point of view, the tests showed compatibility between earth and straw, hemp shiv, or rice husk. The formulation containing rice husk (R) seems to be most interesting. It presented a good result for each durability property tested, i.e., water absorption under low-pressure, dry abrasion, water drop erosion, and impact, and is thus the best compromise. Deeper knowledge of rice husk composite, especially concerning its mechanical resistance, fracture behavior, and hygroscopic buffering ability, would allow an interesting sustainable product to be developed.

The study also aimed to investigate and discuss the relevance of various test procedures to assess the durability of bio-based earth construction materials. For example, the impact test, which is a standardized test, allows the characterization of the material only with the impact diameter. However, it was shown in this study that this parameter alone is not sufficient to characterize the material behavior after an impact, specifically with the addition of bioaggregates. Moreover, as discussed before, the tests presented here, which were the tests intended for earth materials without any bioaggregates, are sometimes difficult to adapt to bio-based materials, such as the sealing of the Karsten tubes or the determination of the absorption coefficient. Further studies are necessary to adapt these procedures to earth construction materials containing bioaggregates.

Other complementary tests could also be performed on earthen materials to assess other durability properties, such as the compressive strength in humid conditions, flammability, and susceptibility for biological development. However, many existing tests, better suited for outdoors-exposed masonry units, can only be used for binder-stabilized earth, such as the water immersion test or the accelerated wet spray erosion test. New tests should, thus, be developed in parallel to indoor and outdoor experiments to be representative of real environmental conditions, thereby contributing to the wider use of these eco-friendly composites by the building industry.

\section{Acknowledgments}

The authors wish to thank the RILEM Technical Committees 274-TCE and 275-HDB for discussions.

\section{Author Contributions}

A. Laborel-Préneron carried out the experiments and wrote the manuscript with support from P. Faria, J.E. Aubert and C. Magniont, P. Faria conceived the study and designed the experiments, C. Magniont and J.E. Aubert were in charge of overall production.

\section{Funding}


French National Research Agency - France (ANR) - project BIOTERRA - ANR - 13 - VBDU - 0005 Villes et Bâtiments Durables

\section{Competing Interests}

The authors have declared that no competing interests exist.

\section{References}

1. Minke G. Building with earth: Design and technology of a sustainable architecture. Basel, Switzerland: Birkhäuser; 2006.

2. Morel JC, Charef R. What are the barriers affecting the use of earth as a modern construction material in the context of circular economy? IOP Conf Ser Earth Environ Sci. 2019; 225: 012053.

3. Aymerich F, Fenu L, Francesconi L, Meloni P. Fracture behaviour of a fibre reinforced earthen material under static and impact flexural loading. Constr Build Mater. 2016; 109: 109-119.

4. Sangma S, Tripura DD. Experimental study on shrinkage behaviour of earth walling materials with fibers and stabilizer for cob building. Constr Build Mater. 2020; 256: 119449.

5. Kouta N, Saliba J, Saiyouri N. Effect of flax fibers on early age shrinkage and cracking of earth concrete. Constr Build Mater. 2020; 254: 119315.

6. Simons A, Bertron A, Roux C, Laborel-Préneron A, Aubert JE, Roques C. Susceptibility of earthbased construction materials to fungal proliferation: laboratory and in situ assessment. RILEM Tech Lett. 2019; 30: 140-149.

7. Rim KA, Ledhem A, Douzane O, Dheilly RM, Queneudec M. Influence of the proportion of wood on the thermal and mechanical performances of clay-cement-wood composites. Cem Concr Compos. 1999; 21: 269-276.

8. Algin HM, Turgut P. Cotton and limestone powder wastes as brick material. Constr Build Mater. 2008; 22: 1074-1080.

9. Bouhicha M, Aouissi F, Kena S. Performance of composite soil reinforced with barley straw. Cem Concr Compos. 2005; 27: 617-621.

10. Faria P, Santos T, Aubert JE. Experimental characterization of an earth eco-efficient plastering mortar. J Mater Civ Eng. 2016; 28: 04015085.

11. Sharma V, Marwaha BM, Vinayak HK. Enhancing durability of adobe by natural reinforcement for propagating sustainable mud housing. Int J Sustain Built Environ. 2016; 5: 141-155.

12. Giroudon M, Laborel-Préneron A, Aubert JE, Magniont C. Comparison of barley and lavender straws as bioaggregates in earth bricks. Constr Build Mater. 2019; 202: 254-265.

13. Gurunathan T, Mohanty S, Nayak KS. A review of the recent developments in biocomposites based on natural fibres and their application perspectives. Compos Part A Appl Sci Manuf. 2015; 77: 1-25.

14. FranceAgriMer. L'observatoire national des ressources en biomasse(ONRB): Evaluation des ressources disponibles en France. FranceAgriMer. 2012. Available from: https://www.franceagrimer.fr/fam/content/download/48820/document/14122016 Publicati on-ONRB-VF.pdf?version=5.

15. Laborel-Préneron A, Aubert JE, Magniont C, Tribout C, Bertron A. Plant aggregates and fibers in earth construction materials: A review. Constr Build Mater. 2016; 111: 719-734. 
16. Binici $H$, Aksogan $\mathrm{O}$, Shah $\mathrm{T}$. Investigation of fibre reinforced mud brick as a building material. Constr Build Mater. 2005; 19: 313-318.

17. Mohamed AE. Improvement of swelling clay properties using hay fibers. Constr Build Mater. 2013; 38: 242-247.

18. Parisi F, Asprone D, Fenu L, Prota A. Experimental characterization of Italian composite adobe bricks reinforced with straw fibers. Compos Struct. 2015; 122: 300-307.

19. Piattoni $Q$, Quagliarini E, Lenci S. Experimental analysis and modelling of the mechanical behaviour of earthen bricks. Constr Build Mater. 2011; 25: 2067-2075.

20. Quagliarini $Q$, Lenci $S$. The influence of natural stabilizers and natural fibres on the mechanical properties of ancient Roman adobe bricks. J Cult Herit. 2010; 11: 309-314.

21. Yetgin Ş, Çavdar Ö, Çavdar A. he effects of the fiber contents on the mechanic properties of the adobes. Constr Build Mater. 2008; 22: 222-227.

22. Ashour $\mathrm{T}$, Wieland $\mathrm{H}$, Georg $\mathrm{H}$, Bockisch FJ, Wu W. The influence of natural reinforcement fibres on insulation values of earth plaster for straw bale buildings. Mater Des. 2010; 31: 4676-4685.

23. Binici H, Aksogan O, Bodur MN, Akca E, Kapur S. Thermal isolation and mechanical properties of fibre reinforced mud bricks as wall materials. Constr Build Mater. 2007; 21: 901-906.

24. Magniont C, Escadeillas G, Coutand M, Oms-Multon C. Use of plant aggregates in building ecomaterials. Eur J Environ Civ Eng. 2012; 21: 17-33.

25. Cerezo V. Propriétés mécaniques, thermiques et acoustiques d'un matériau à base de particules végétales: Approche expérimentale et modélisation théorique. Lyon: Institut National des Sciences Appliquées. 2005.

26. Diquélou Y, Gourlay E, Arnaud L, Kurek B. Impact of hemp shiv on cement setting and hardening: Influence of the extracted components from the aggregates and study of the interfaces with the inorganic matrix. Cem Concr Compos. 2015; 55: 112-121.

27. del Valle-Zermeño R, Aubert JE, Laborel-Préneron A, Formosa J, Chimenos JM. Preliminary study of the mechanical and hygrothermal properties of hemp-magnesium phosphate cements. Constr Build Mater. 2016; 105: 62-68.

28. Hamard E, Morel JC, Salgado F, Marcom A, Meunier N. A procedure to assess the suitability of plaster to protect vernacular earthen architecture. J Cult Herit. 2013; 14: 109-115.

29. Gomes MI, Gonçalves TD, Faria P. Characterization of earth-based mortars for rammed earth repair. Earth Constr Tradit. 2015; 1: 259-276.

30. Flament $\mathrm{C}$. Valorisation des fines de lavage de granulats: Application à la construction en terre crue. Béthune: Université d’Artois; 2013.

31. Balčiūnas G, Žvironaitė J, Vejjelis S, Jagniatinskis A, Gaidučis S. Ecological, thermal and acoustical insulating composite from hemp shives and sapropel binder. Ind Crops Prod. 2016; 91: 286-294.

32. Carter GW, Cannor AM, Mansell DS. Properties of bricks incorporating unground rice husks. Build Environ. 1982; 17: 285-291.

33. Chiang KY, Chou PH, Hua CR, Chien KL, Cheeseman C. Lightweight bricks manufactured from water treatment sludge and rice husks. J Hazard Mater. 2009; 171: 76-82.

34. Rahman MA. Properties of clay-sand-rice husk ash mixed bricks. Int J Cem Compos Lightweight Concr. 1987; 9: 105-108. 
35. Chabannes M, Bénézet JC, Clerc L, Garcia-Diaz E. Use of raw rice husk as natural aggregate in a lightweight insulating concrete: An innovative application. Constr Build Mater. 2014; 70: 428438.

36. Serrano T, Borrachero MV, Monzó JM, Paya J. Morteros aligerados con cascarilla de arroz: Diseño de mezclas y evaluación de propiedades. Dyna. 2012; 79: 128-136.

37. Salas J, Alvarez M, Veras J. Lightweight insulating concretes with rice husk. Int J Cem Compos Lightweight Concr. 1986; 8: 171-180.

38. Antunes A, Faria P, Bras A, Silva V. Rice husk-earth based composites: A novel bio-based panel for buildings refurbishment. Constr Build Mater. 2019; 221: 99-108.

39. Muntohar AS. Engineering characteristics of the compressed-stabilized earth brick. Constr Build Mater. 2011; 25: 4215-4220.

40. Laborel-Préneron A, Aubert JE, Magniont C, Lacasta A, Haurie L. Fire behavior of bio-based earth products for sustainable buildings. Acad Int J Civ Eng. 2017; 35: 160-165.

41. Laborel-Préneron $A$, Ouédraogo $K$, Simons $A$, Labat $M$, Bertron $A$, Magniont $C$, et al. Laboratory test to assess sensitivity of bio-based earth materials to fungal growth. Build Environ. 2018; 142: 11-21.

42. Medvey B, Dobszay G. Durability of stabilized earthen constructions: A review. Geotech Geol Eng. 2020; 38: 2403-2425.

43. Beckett $C T$, Jaquin PA, Morel JC. Weathering the storm: $A$ framework to assess the resistance of earthen structures to water damage. Constr Build Mater. 2020; 242: 118098.

44. Cid-Falceto J, Mazarrón FR, Cañas I. Assessment of compressed earth blocks made in Spain: International durability tests. Constr Build Mater. 2012; 37: 738-745.

45. Van Damme H, Houben H. Earth concrete. Stabilization revisited. Cem Concr Res. 2018; 114: 90-102.

46. German Standard. Lehmsteine - Begriffe, anforderungen, prüfverfahren. DIN 18945. Deutsches Institut für Normung. 2013.

47. NZS 4298. Materials and workmanship for earth buildings. 1998.

48. Simons A, Laborel-Préneron A, Bertron A, Aubert JE, Magniont C, Roux C, et al. Development of bio-based earth products for healthy and sustainable buildings: Characterization of microbiological, mechanical and hygrothermal properties. Matér Tech. 2015; 103. DOI: 10.1051/mattech/2015011.

49. Laborel-Préneron A, Magniont C, Aubert JE. Characterization of barley straw, hemp shiv and corn cob as resources for bioaggregate based building materials. Waste Biomass Valor. 2017; 9: 1095-1112.

50. Amziane S, Collet F, Lawrence M, Magniont C, Picandet V. Round robin test for hemp shiv characterization. In Bio-aggregates based building materials: State of the art report of the RILEM Technical Committee 236-BBM. Dordrecht: Springer; 2017.

51. Laborel-Préneron A, Aubert JE, Magniont C, Maillard P, Poirier C. Effect of plant aggregates on mechanical properties of earth bricks. J Mater Civ Eng. 2017; 29: 04017244.

52. Barbera G, Barone G, Mazzoleni P, Scandurra A. Laboratory measurement of ultrasound velocity during accelerated aging tests: Implication for the determination of limestone durability. Constr Build Mater. 2012; 36: 977-983.

53. Aubert JE, Gasc-Barbier M. Hardening of clayey soil blocks during freezing and thawing cycles. Appl Clay Sci. 2012; 65-66: 1-5. 
54. Millogo Y, Morel JC, Aubert JE, Ghavami K. Experimental analysis of pressed adobe blocks reinforced with Hibiscus cannabinus fibers. Constr Build Mater. 2014; 52: 71-78.

55. Mattone R. Sisal fibre reinforced soil with cement or cactus pulp in bahareque technique. Cem Concr Compos. 2005; 27: 611-616.

56. German Standard. Earth plasters. Terms and definitions, requirements, test methods DIN 18947. 2013.

57. Karsten R. Bauchemie für Studium und Praxis. 7th ed. Haslach, 1983.

58. EN 16302. Conservation of cultural heritage. Test methods. Measurement of water absorption by pipe method. British Standards Institution, 2013.

59. Stazi F, Nacci A, Tittarelli F, Pasqualini E, Munafò P. An experimental study on earth plasters for earthen building protection: The effects of different admixtures and surface treatments. J Cult Herit. 2016; 17: 27-41.

60. Hendrickx R. Using the Karsten tube to estimate water transport parameters of porous building materials: The possibilities of analytical and numerical solutions. Mater Struct. 2013; 46: 1309-1320.

61. ISO 7892. Vertical building elements - Impact resistance tests - Impact bodies and general test procedures. ISO. 1988.

62. EN 13947. Thermal insulation products for building applications - Determination of the resistance to impact of external thermal insulation composite systems (ETICS). CEN. 2002.

63. Magalhaes AC, Veiga R. Comparison of "in-situ" mechanical tests on masonry mortars: Sphere impact and controlled penetration test. Proceedings of the International Conference on Heritage, Weathering and Conservation; 2006 June 21-24; Madrid, Spain. London: CRC Press.

64. Flores-Colen I, de Brito J, de Freitas V. Expected render performance assessment based on impact resistance in situ determination. Constr Build Mater. 2009; 23: 2997-3004.

65. Coletti C, Maritan L, Cultrone G, Mazzoli C. Use of industrial ceramic sludge in brick production: Effect on aesthetic quality and physical properties. Constr Build Mater. 2016; 124: 219-227.

66. Faria P, Silva V, Jamú N, Dias I, Gomes MI. Evaluation of air lime and clayish earth mortars for earthen wall renders. In Vernacular Heritage and Earthen Architecture. Boca Raton: CRC Press; 2013.

67. Bras A, Antunes A, Laborel-Préneron A, Ralegaonkar R, Shaw A, Riley $M$, et al. Optimisation of bio-based building materials using image analysis method. Constr Build Mater. 2019; 223: 544-553.

68. Faria P, Santos T, Aubert JE. Experimental Characterization of an Earth Eco-Efficient Plastering Mortar. J Mater Civ Eng. 2016; 28: 04015085.

69. Frencham GJ. The Performance of Earth Building. Geelong: Deakin University; 1982.

70. Heathcote KA. Durability of earthwall buildings. Constr Build Mater. 1995; 9: 185-189.

71. Ashour $\mathrm{T}, \mathrm{Wu} \mathrm{W}$. The influence of natural reinforcement fibers on erosion properties of earth plaster materials for straw bale buildings. J Build Apprais. 2010; 5: 329-340.

72. Bui QB, Morel JC, Venkatarama Reddy BV, Ghayad W. Durability of rammed earth walls exposed for 20 years to natural weathering. Build Environ. 2009; 44: 912-919. 


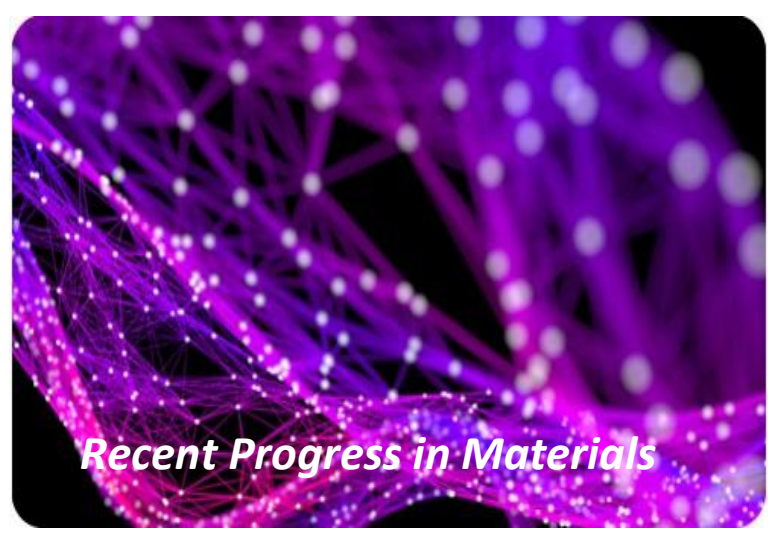

Enjoy Recent Progress in Materials by:

1. Submitting a manuscript

2. Joining in volunteer reviewer bank

3. Joining Editorial Board

4. Guest editing a special issue

For more details, please visit:

http://www.lidsen.com/journals/rpm 